Título do Trabalho

\title{
ESTUDO DO APROVEITAMENTO DO CASCALHO DE PERFURAÇÃO DE POÇOS COMO MATERIAL DE CONSTRUÇÃO.
}

Nome do Autor(a) Principal

Myckelle Michely da Silva Ferreira

Nome do (a) Orientador (a)

Aline da Silva Ramos Barboza

Instituição ou Empresa

Universidade Federal de Alagoas - UFAL

Instituição de Fomento

Programa de Recursos Humanos - PRH 40

Email de Contato

myckellemichely@hotmail.com

Palavra-chave: Cascalho. Estudo. Aproveitamento.

\section{INTRODUÇÃO}

Com o crescimento dos centros urbanos, cresce também a necessidade de preservação dos recursos naturais e dos espaços destinados à população. Dessa forma, a geração de resíduos tem se tornado uma preocupação constante para as administrações públicas e soluções tecnologicas para o melhor aproveitamento desses materiais vem sendo incentivada nos diversos processos produtivos. 
A indústria petrolífera, durante suas operações produz resíduos líquidos, gasosos ou sólidos que podem contaminar o meio ambiente e à saúde pública. Através da adesão de regulamentos e leis, as indústrias e empresas buscam reduzir os efeitos nocivos desses resíduos a níveis aceitáveis.

O cascalho de perfuração é um resíduo abundante e bastante complexo, resultante do processo de perfuração de poços de petróleo. O cuidado com a disposição e tratamento desse resíduo deve receber atenção especial, pois hidrocarbonetos e sais solúveis fazem parte de sua constituição e estes podem trazer graves consequências ao meio ambiente. O fluido de perfuração, a depender de sua natureza, é quem confere possível contaminação ao cascalho de perfuração.

No polo de Pilar em Alagoas, existia até Junho de 2013 entre 8 e 10 mil toneladas de cascalho de perfuração, contaminados por fluido a base de água e de fluido a base de óleo. Esse volume foi armazenado em um ano e só tende a aumentar, pois, à medida que a perfuração dos poços avança mais material é depositado.

Diante dessa realidade e da obrigatoriedade do cumprimento das leis e normas que regulamentam o tratamento dos resíduos, é necessário que estudos sejam realizados para que ocorra uma melhor caracterização desses resíduos, apontando possíveis potencialidades de utilização e consequentemente uma melhor forma para o seu aproveitamento.

A utilização do cascalho de perfuração como material de construção é uma alternativa que visa diminuir o acúmulo de tal resíduo, reduzir a demanda de recursos naturais e ajudar na preservação do meio ambiente.

\section{OBJETIVO GERAL}

Este trabalho tem como objetivo principal fazer uma caracterização do cascalho de perfuração de alguns poços da região de Alagoas e estabelecer conclusões parciais que 
possibilitem a aplicação futura do resíduo estudado, como material de construção. Para isso, será feito um estudo inicial de caracterização do material, com vistas à geração de um produto com características de desempenho que atendam as recomendações da Associação Brasileira de Normas Técnicas.

\section{OBJETIVOS ESPECÍFICOS}

Investigar as principais propriedades físicas, químicas e mineralógicas do cascalho de perfuração de poços por meio de experimentação nos laboratórios da Universidade Federal de Alagoas. Com o resultado das avaliações teóricas e experimentais, poderão ser realizadas análises comparativas com outros resíduos já melhor estudados, caracterizando assim, a potencialidade de utilização do cascalho.

\section{METODOLOGIA}

O desenvolvimento do trabalho teve como etapa inicial uma revisão bibliográfica relacionada ao tema central de forma a investigar e caracterizar o potencial de aproveitamento do resíduo de cascalho na construção civil.

Posteriormente, foi desenvolvida a etapa inicial de experimentação tendo como suporte a infraestrutura física e de pessoal do Laboratório de Estruturas e Materiais do Centro de Tecnologia da Universidade Federal de Alagoas. Com o resultado das avaliações teóricas e experimentais, obtidas até o presente momento é possível realizar análises preliminares sobre os resíduos estudados.

\section{RESULTADOS}


As amostras analisadas no presente trabalho foram coletadas no polo da Petrobras em Pilar - AL, sendo retirados aproximadamente $16 \mathrm{Kg}$ de cascalho de perfuração a base de água e $18 \mathrm{Kg}$ de cascalho a base de óleo. Os montes de cascalho de perfuração encontravam-se em um terreno sem proteção contra chuva e intempéries, separados pela origem do fluido de perfuração. Os experimentos foram realizados no laboratório de Geotecnia da Universidade Federal de Alagoas - UFAL e no laboratório de Materiais e foram executados conforme as orientações da NBR que padroniza cada ensaio.

Os resíduos ao chegarem ao laboratório foram preparados para os ensaios, conforme a NBR 6457. Para a caracterização física dos resíduos foram realizados os ensaios de peneiramento, sedimentação, umidade, massa específica dos grãos de solo, limite de contração, limite de liquidez e limite de plasticidade.

Com o ensaio de peneiramento e sedimentação foram formadas as curvas de distribuição granulométrica, que possibilitam observar que os resíduos apresentam um alto teor de finos em sua composição. As Figuras 1 e 2 apresentam as curvas de distribuição granulométrica para os resíduos analisados.

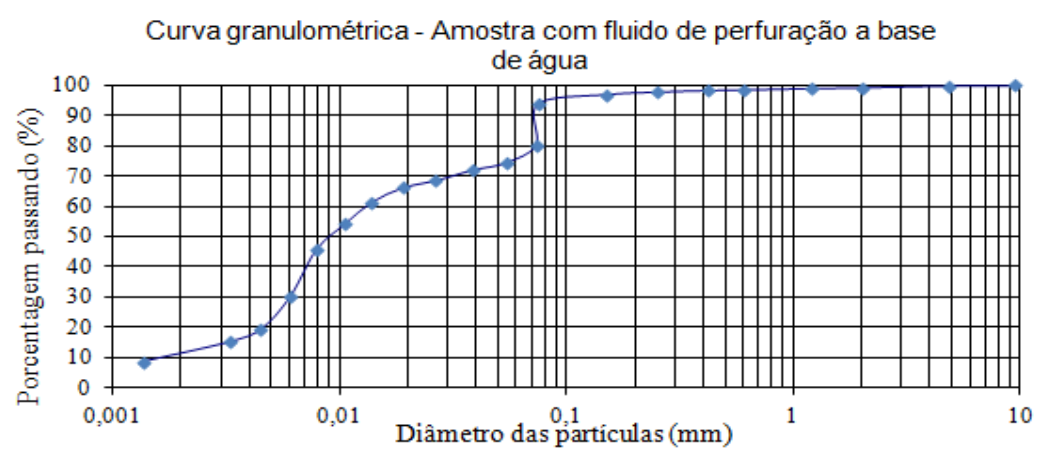

Figura 1. Curva de distribuição granulométrica do material com fluido de perfuração base água. 
Curva granulométrica - amostra com fluido de perfuração base óleo

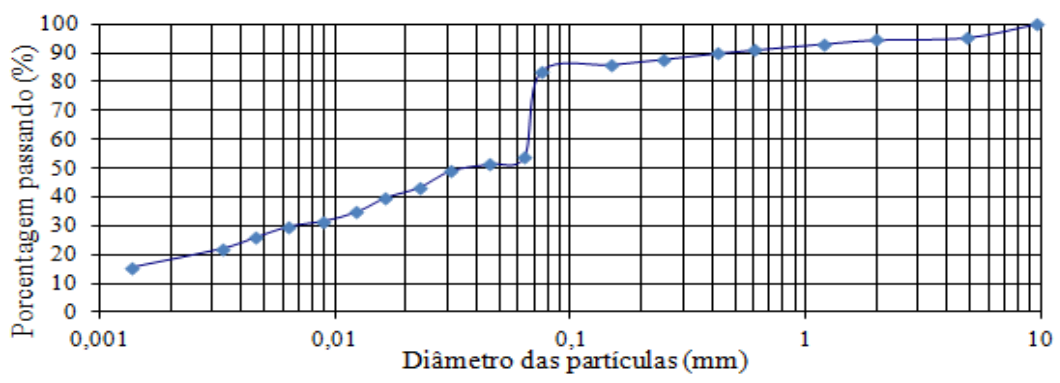

Figura 2. Curva de distribuição granulométrica do material com fluido de perfuração base óleo.

A tabela 1 apresenta a porcentagem de cada faixa granulométrica dos resíduos estudados, segundo a ABNT.

Tabela 1. Valores do ensaio de granulometria

\begin{tabular}{|l|c|c|c|c|c|c|}
\hline \multirow{2}{*}{ Material } & \multirow{2}{*}{$\begin{array}{c}\text { Pedregulho } \\
(\%)\end{array}$} & \multicolumn{3}{|c|}{ Areia (\%) } & Silte & Argila \\
\cline { 3 - 5 } & grossa & média & fina & $(\%)$ & $(\%)$ \\
\hline Base água & 1 & 1 & 1 & 23 & 64 & 10 \\
\hline Base óleo & 5 & 5 & 3 & 37 & 32 & 18 \\
\hline
\end{tabular}

A massa especifica dos grãos de solo foi obtida segundo a NBR - 6508/84. Encontramos uma massa específica dos grãos de solo da amostra a base água de 2,55 $\mathrm{g} / \mathrm{cm}^{3}$, já para a amostra a base óleo a massa específica foi de $2,44 \mathrm{~g} / \mathrm{cm}^{3}$.

Os limites de consistência dos resíduos demonstram que o resíduo a base de água é altamente plástico e apresenta um alto valor para o seu limite de liquidez. Quanto ao cascalho com fluido de perfuração a base de óleo, encontramos uma baixa plasticidade, menor limite de liquidez e apresenta menor índice de contração quando comparado com o outro resíduo.

Os valores encontrados nos ensaios podem ser visualizados pela Tabela 2. É importante lembrar esses valores podem estar comprometidos pelo fato de existir a influência de substâncias químicas que podem prejudicar os resultados, como por exemplo, a parafina. 
Tabela 2. Limites de consistência

\begin{tabular}{|l|c|c|c|}
\hline Material & $\begin{array}{c}\text { Limite de } \\
\text { plasticidade } \\
(\%)\end{array}$ & $\begin{array}{c}\text { Limite de } \\
\text { liquidez } \\
(\%)\end{array}$ & $\begin{array}{c}\text { Índice de } \\
\text { plasticidade } \\
(\%)\end{array}$ \\
\hline Base água & 33,2 & 51,6 & 18,4 \\
\hline Base óleo & 29 & 35 & 6 \\
\hline
\end{tabular}

Os ensaios de caracterização química e mineralógica estão em andamento.

\section{CONSIDERAÇÕES FINAIS}

Os resultados experimentais encontrados até o momento permitem algumas análises preliminares sobre os resíduos que estão sendo estudados. À medida que os ensaios de caracterização química e mineralógica forem sendo realizados e os seus respectivos resultados forem relacionados, encontraremos uma análise mais completa e detalhada sobre os resíduos.

\section{REFERÊNCIAS}

ABNT. NBR 1007: coleta de amostras de resíduos - amostragem de resíduos sólidos. Rio de Janeiro, 2004.

ABNT. NBR 6457: - preparação para ensaio de compactação e caracterização. Rio de Janeiro, 1986.

ABNT. NBR 7181: análise granulométrica - procedimento para a análise granulométrica. Rio de Janeiro, 1984.

ABNT. NBR 6508: massa especifica dos grãos de solo - procedimento para determinação dos grãos de solo. Rio de Janeiro, 1984. 


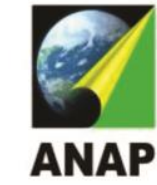

ABNT. NBR 6459: limite de liquidez - determinação do limite de liquidez. Rio de Janeiro, 1984.

ABNT. NBR 7180: limite de plasticidade - determinação do limite de plasticidade. Rio de Janeiro, 1984.

Medeiros, L. C., Utilização de Cascalho de Perfuração de Poços de Petróleo para a Produção de Cerâmica Vermelha, Tese de Doutorado, Pontifícia Universidade Católica do Rio de Janeiro, 2009. 